\title{
THROUgh-Hole EXIT CHARACTERISTICS In DRILling OF Ti6Al4V AND QUALITY IMPROVEMENT OF HOLE EXIT
}

\author{
Quanli Han and Hongqiang Wan \\ School of Mechanical and Electronical Engineering, XiAn Technological University, \\ XiAn, China
}

\begin{abstract}
The removal of macro-burrs formed after drilling has always been a difficult engineering problem, especially on different-machined materials with through holes. This paper aims at presenting an investigation into hole exit characteristics of Ti6Al4V drilled. Plastic deformation at the end of the cutting process or blanking results into the forming of burr, whose degree of impact is mostly affected by the processing parameters, especially the axial feed. Series experiments were conducted to analysis the effect of processing parameter on formed burr. The volume of burr has great effect on work-piece quality and product cost, the burr height formed easily decreases because great attention from scholars and engineers has been paid to, while the burr width size despised naturally plays a great influence on product quality and machining cost. The new de-burring tool are designed and applied in experiment, the decrease in burr width is obviously found, so the removal of burrs becomes much little than that gotten in traditional tool. The resulting indicates a promising future of de-burring in practical application Journals.
\end{abstract}

\section{KEYWORDS}

Drilling, Hole exit quality, Burr, De-burring

\section{INTRODUCTION}

Titanium and it alloys (Ti) has been drawn a widely industrial attention to with great passion, which can be viewed in following fields like aerospace, automobile, medical, chemical, military, sporting goods and etc. And the increasing popularity of Ti naturally results from their superior properties and availability in the earth's source as well as price stability in market. The dramatic growth of Ti industry in the past several decades has to be attributed to technology development in processes for $\mathrm{Ti}$. Because of process ability of $\mathrm{Ti}$, traditional and nontraditional processes are used in machining of them; the former includes turning, milling and grinding while the latter does ultrasonic assisted machining, electro-discharge machining and cryogenic machining.

Ti classified as difficult-to-machine material shows its special characteristics in thermal conductivity and affinity to tool materials and hardness and strength at high temperatures. As one of the final steps in the fabrication of components, Drilling Ti is very vital for many applications because this has considerable economical concerns and accounts for a large percentage of all machining processes. Up to now many researchers' works have been done by researchers, and several papers related to drilling Ti have been published. Pei reviewed drilling processes for Ti comprehensively to improve the cost-effectiveness of currently-available drilling process and/or to develop cost-effective drilling processes [1]. Dornfeld investigated process conditions and drill geometry during the drilling burr formation in $\mathrm{Ti}$ [2]. Cantero studied the evolution of drill wear, quality of machined hole in the dry drilling of alloy Ti6Al4V [3]. Lazoglu estimated the temperature evolution of drill in Ti6Al4V drilling under various process conditions [4]. Karagade 
International Journal of Recent Advances in Mechanical Engineering (IJMECH) Vol.8, No.1, February 2019

developed a comprehensive finite element model to evaluate temperature distribution in drilling of Ti considering a variable heat partition model and ploughing forces [5]. Sharif conducted experiments to investigate performance of coated drill when drilling Ti6Al4V [6]. Rahim worked on high speed drilling of Ti in the direction of uncoated drill and palm oil as MQL lubricant $[7,8]$. Pecat brought out chip extraction index to identify suitable cutting parameters and process conditions for drilling Ti6A14V [9]. To the people's surprise, Ti/others (CFRP , graphite , bismaleimide or Composite) Stack drilling has greatly drawn researchers' attention for their increasing widely application, processing optimization, tool wear and other related topics in drilling process has been seen in literature[10-12].

Expect above mechanical drilling of $\mathrm{Ti}$, researchers brought out some advanced drilling process recently to meet the requirement in productivity and precision of part. Spakal and Plaza carried out work on micro-EDM drilling of Ti6Al4V in the field of optimization of process parameters and creative design of drill respectively $[13,14]$. Sakurai and Okamura made pioneering work of low frequency vibration drilling of titanium alloy $[15,16]$.

Hole drilling quality, specially hole exit quality takes great effect on product assembly feature. Scholars have research on hole exit defects in aspect of drilling mechanism, drill bit structure, cutting parameters optimization, and so on. And their achievements have promoted drilling technique development greatly. However, drilling defects has inherently resulted from the pushing cutting in semi-enclosed working zone and difficulty of chip removal, and therefore advanced drilling fails to meet the demand of high precision and efficiency hole-making. In-depth study on hole exit features should be made continuously. To analyses hole exit characteristics, we conducted experiments to investigate the effect of processing parameters on hole exit (burr), and then designed a new tool to de-burr for avoiding the increase in the cost of manufacturing.

\section{EXPERIMENT SETUP}

The alpha-beta titanium alloy Ti6Al4V block, as work-piece material, was used in this study. A bar of Ti with the diameter of $80 \mathrm{~mm}$ was cut into $80 \mathrm{~mm}$ thick disks and slotted to produce an equilateral triangular section with a side length of $20 \mathrm{~mm}$ as sown in Figure 1a. Holes of $5.5 \mathrm{~mm}$ holes were drilled that exit on the centreline of slot. Burrs were observed after hole sectioning using wire EDM at measurement locations labelled $\mathrm{A}$ and $\mathrm{E}$ in Figure 1b, which represented flat exit surface conditions, and those labelled B , C, D, F, G and H, which represent curved exit condition. Both exit surfaces were examined because exit surface curvature is known to affect burr development and the resulting burr formations. And the nominal chemical composition of Ti6Al4V is shown in Table 1.

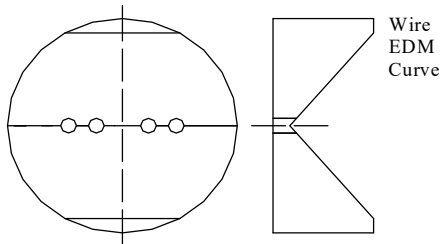

(a)

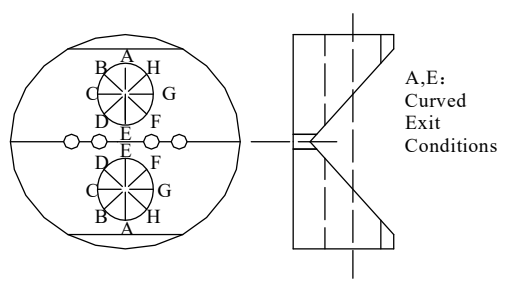

(b)

Figure 1. Ti6A14Vwith (a) EDM Cross-Setting Detail and (b) Burr Measurement Locations 
International Journal of Recent Advances in Mechanical Engineering (IJMECH) Vol.8, No.1, February 2019

Table 1. Nominal composition of Ti6Al4V(weight percent).

\begin{tabular}{|l|l|l|l|l|l|l|l|l|}
\hline Al & $\mathbf{V}$ & $\mathbf{F e}(\mathbf{m a x})$ & $\mathbf{S i}(\max )$ & $\mathbf{C}(\mathbf{m a x})$ & $\mathbf{N}(\mathbf{m a x})$ & $\mathbf{H}(\mathbf{m a x})$ & $\mathbf{O}(\mathbf{m a x})$ & Titanium \\
\hline $5.5-6.8$ & $3.5-4.5$ & 0.3 & 0.15 & 0.1 & 0.05 & 0.015 & 0.15 & Balance \\
\hline
\end{tabular}

In this study, drilling operations were performed on BJXK5076 five axis high-speed machining center. As shown in Fig. 2, a Kistler three-direction stationary dynamometer (9257B) and supporting Kislter charge amplifier (type 5070) were used. And data acquisition board and Kistler software were utilized for a three-direction cutting force measurement. In this study, the drillings recommended by tool manufactures were selected for drilling tests. The composition of the cutter matrix is $\mathrm{WC} 8 \% \mathrm{Co}$, and the thickness of the TiAIN coating is $1 \sim 3 \mu \mathrm{m}$. The detailed parameters of cutter used in this study are shown in Table 2, the novel fixture designed was used to clamp the work-piece effectively also seen in Fig. 2. And the cutting parameters for drilling Ti6A14V are given in Table 3.

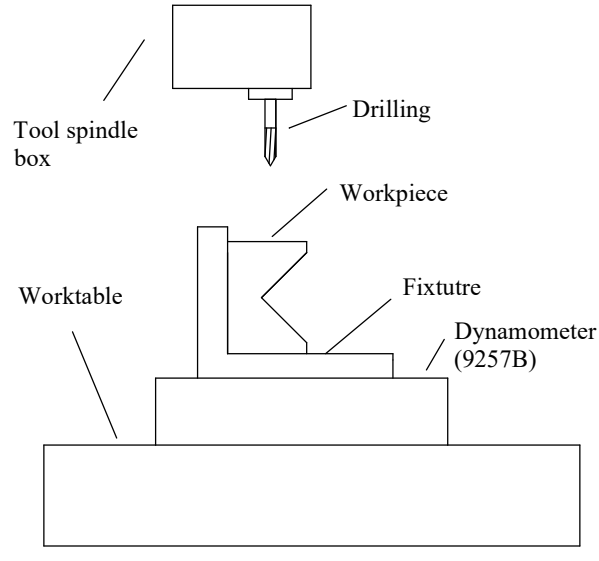

(a)
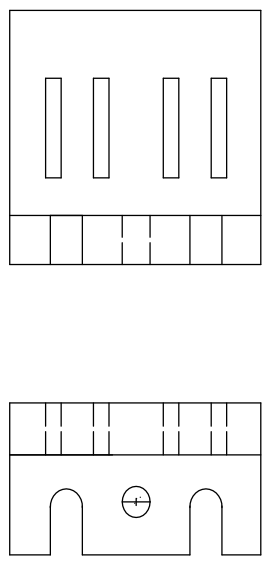

(b)

Figure 2. Schematic of Experiment designed (a) Experimental setup and (b) Fixture

Table 2. Main parameters of the drilling

\begin{tabular}{|l|l|l|l|l|l|}
\hline $\begin{array}{l}\text { Material } \\
\text { s }\end{array}$ & $\begin{array}{l}\text { Top } \\
\text { angle }\end{array}$ & Spiral angle & $\begin{array}{l}\text { Transverse edge oblique } \\
\text { angle }\end{array}$ & $\begin{array}{l}\text { Transverse edge } \\
\text { length(mm) }\end{array}$ & Tip \\
\hline Tungsten & $118^{\circ}$ & $25^{\circ}$ & $66^{\circ}$ & 0.60 & Balance \\
\hline
\end{tabular}

Table 3. The cutting parameters for drilling Ti6Al4V

\begin{tabular}{|l|l|l|l|l|l|}
\hline $\begin{array}{l}\text { Cooling } \\
\text { condition }\end{array}$ & $\begin{array}{l}\text { Cutting speed } \\
(\mathbf{r} / \mathbf{m i n})\end{array}$ & $\begin{array}{l}\text { Axial feed } \\
(\mathbf{m m} / \mathbf{r})\end{array}$ & $\begin{array}{l}\text { Hole } \\
\text { diameter } \\
(\mathbf{m m})\end{array}$ & $\begin{array}{l}\text { Hole } \\
\text { depth } \\
(\mathbf{m m})\end{array}$ & $\begin{array}{l}\text { Axial distance of } \\
\text { tool machined } \\
(\mathbf{m m})\end{array}$ \\
\hline Water & $30,60,90,110$ & $0.07,0.08,0.09,0.11$ & 8 & 35 & 85 \\
\hline
\end{tabular}

The experiment processes detailed the following steps. During drilling, tool went forward $1.5 \mathrm{~mm}$ then back $1.0 \mathrm{~mm}$, then went forward while stop turning. Because the processing parameters takes great effect on hole exit quality, especially the axial feed. Series experiments with various axial feed were conducted to analysis the effect of processing parameter on formed burr. After drilling, one work-piece was cutting into two halves, in order to investigate the whole structure of hole. The influence of processing parameters to hole exit quality was analyzed by the observation of 
International Journal of Recent Advances in Mechanical Engineering (IJMECH) Vol.8, No.1, February 2019

the geometry of burr with the Hirox KH-1000 optical microscope attached to personal computer. The two directions were used to get the burr height and width, and for each observation the observed points on hole exit was chosen as Fig.1 (b). On each point, the burr height and width were measured on the drawing of through hole of work-piece according to the Fig. 3, and then, the average of measurement result above was obtained to value the formed burr height and width of hole. To improve hole exit quality, new de-burring tools was designed, the designed objects in new tool was to decrease plastic deformation at the end of the cutting process, which was seen in Fig. 4. And to validate the function of new designed tool, the comparative experiments of new designed and traditional tool were conducted. To analysis the effect of force on burr formation, the force at the beginning of burr was determined, according to the measurement curve of force from the stationary dynamometer.

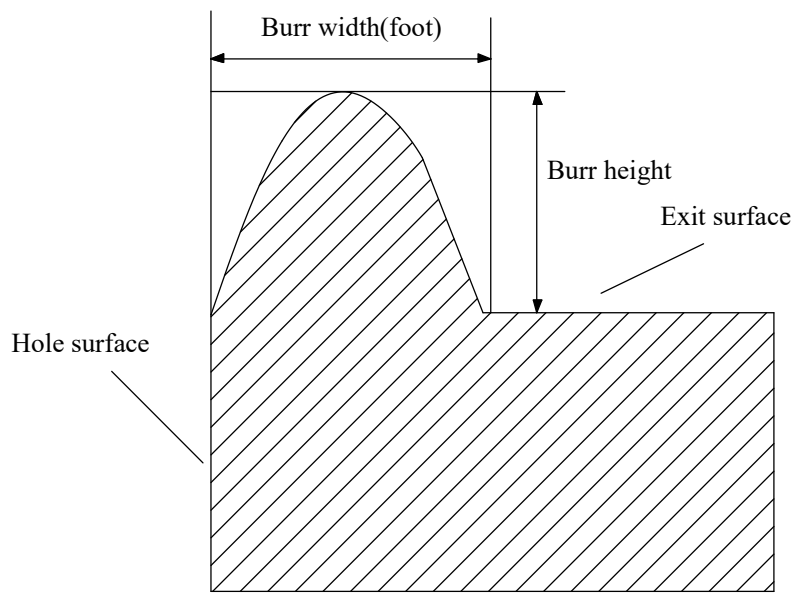

Figure 3. Schematic of Experiment designed (a) Experimental setup and (b) Fixture

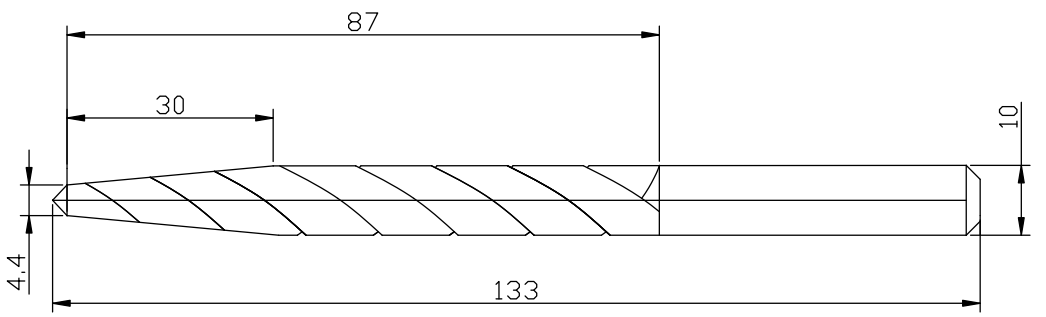

Figure 4. Schematic of tool designed in study

\section{RESUlTS AND DisCUSSIONS}

Fig. 5 and Fig. 6 show the exit burr widths and heights under different spindle speeds and feed rates. Overall, the burr width is larger than burr height when the processing parameters are kept same. The variation of the burr heights ranged between $10 \mu \mathrm{m}$ and $70 \mu \mathrm{m}$ at exit hole, while that of burr width did between 125 and $450 \mu \mathrm{m}$. One noticed point is lack of the value of burr when the processing parameters are the spindle speed of $30 \mathrm{r} / \mathrm{min}$ and the feed rates of $0.09 \mathrm{~mm} / \mathrm{r}$ and 0.10 $\mathrm{mm} / \mathrm{r}$. Because the processing condition is the combination of too low spindle speed and tool high feed rates, it is unable to process hole. The machining energy in processing condition above on tool is less than the specific energy of work-piece, the volume of removal material is zero, so the value of burr height and width at exit is zero, as shown in Fig.5 and 6. 
International Journal of Recent Advances in Mechanical Engineering (IJMECH) Vol.8, No.1, February 2019

When the spindle speed keeps constant, the burr width and height increases with the increase in feed rate. The minimum change of burr width is seen in spindle speed of $90 \mathrm{r} / \mathrm{m}$ when increasing in feed rate, while that of burr height id done in spindle speed of $60 \mathrm{r} / \mathrm{m}$. The change of burr width and height are $145 \mu \mathrm{m}$ and $9 \mu \mathrm{m}$ separately. When the speed rate keeps constant, the burr height increases with the increase in spindle speed, and the minimum burr width is seen in spindle speed of $90 \mathrm{r} / \mathrm{m}$.

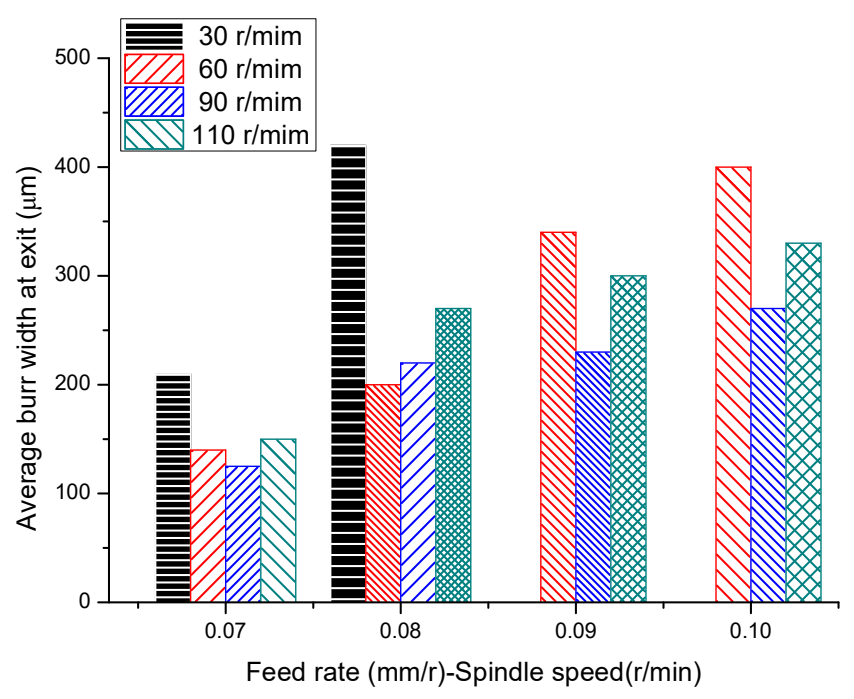

Figure 5. Average burr width at exit

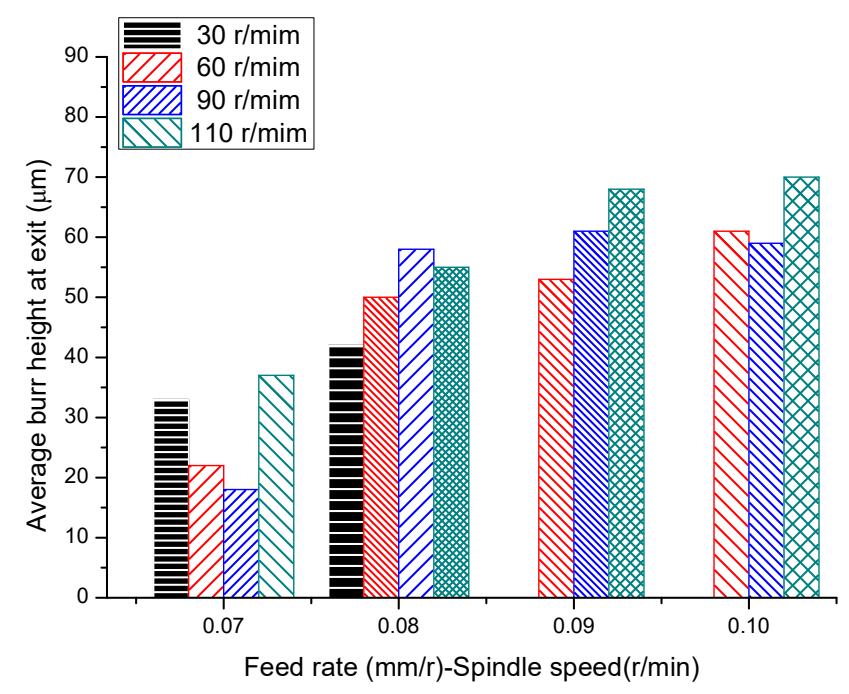

Figure 6. Average burr height at exit

The volume of burr determines cost of taking removal materials away from the work-piece. To calculate the volume of de-burring, the cross-shape of burr is assumed to be triangle, the volume of burr is determined according to the product of the cross sectional area and hole perimeter. The calculation of de-burring volume with increase in feed rate and spindle speed is seen in Fig.7. 
International Journal of Recent Advances in Mechanical Engineering (IJMECH) Vol.8, No.1, February 2019

From Fig.7, when the spindle speed keep constant, the burr volume increases with the increase in feed rate, and with the increase in feed rate, the rise by a small margin is seen. When the speed rate keep constant, the burr volume declines and then climbs up with the increase in spindle speed, And the minimum burr volume is commonly seen in spindle speed of $90 \mathrm{r} / \mathrm{m}$. The most popular processing parameters is feed rate of $0.08 \mathrm{~mm} / \mathrm{r}$ when the burr volume and rate of feed rate is the minimum, to be close to $1.25 \times 106 \mu \mathrm{m} 2$. That means the burr volume is the least while the feed rate is the fastest, which brings great helpful result in manufacturing process.

The thrust forces and torque of tool in drilling with various spindle speed and feed rate were listed in Fig. 8 and Fig. 9 respectively. Overall, the variation of the thrust forces ranged between $730 \mathrm{~N}$ and $1370 \mathrm{~N}$ when drilling, and that of thrust torque did between $258 \mathrm{~N} \cdot \mathrm{mm}$ and $1021 \mathrm{~N} \cdot \mathrm{mm}$.

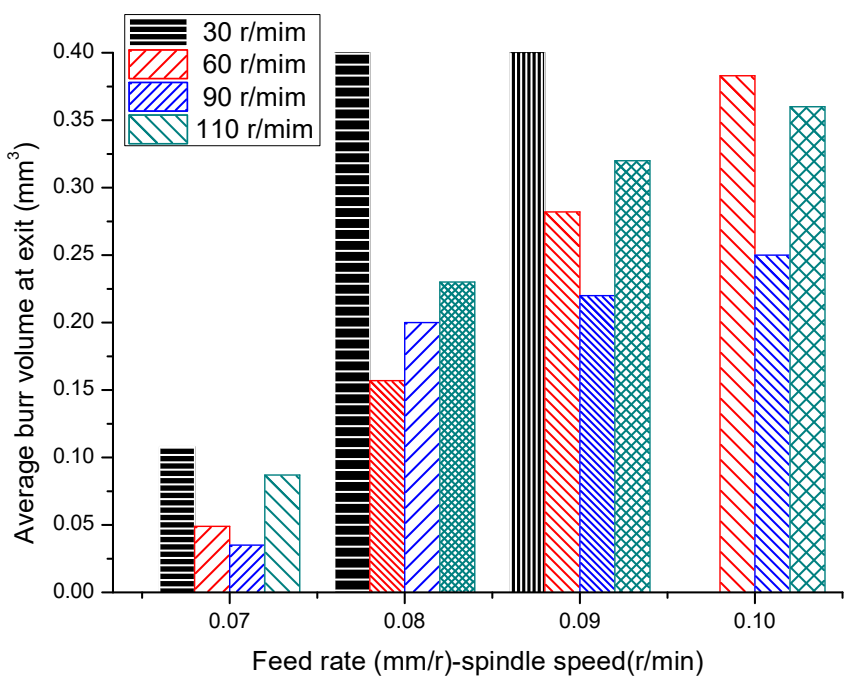

Figure 7. Average burr volume at exit

From Fig.8, when the spindle speed keeps constant, the thrust force increases with the increase in feed rate, and with the increase in feed rate, the rise by a small margin is seen. When the speed rate keeps constant, the thrust force rises with the increase in spindle speed, and the rise by a small margin is seen with the increase in feed rate.

Similarly in Fig.9, when the spindle speed doesn't change, the thrust torque increases with the increase in feed rate, and the small range of increase in torque is found. When the speed rate doesn't , the thrust torque rises with the increase in spindle speed and the rise by a large margin is seen with the increase in feed rate. 


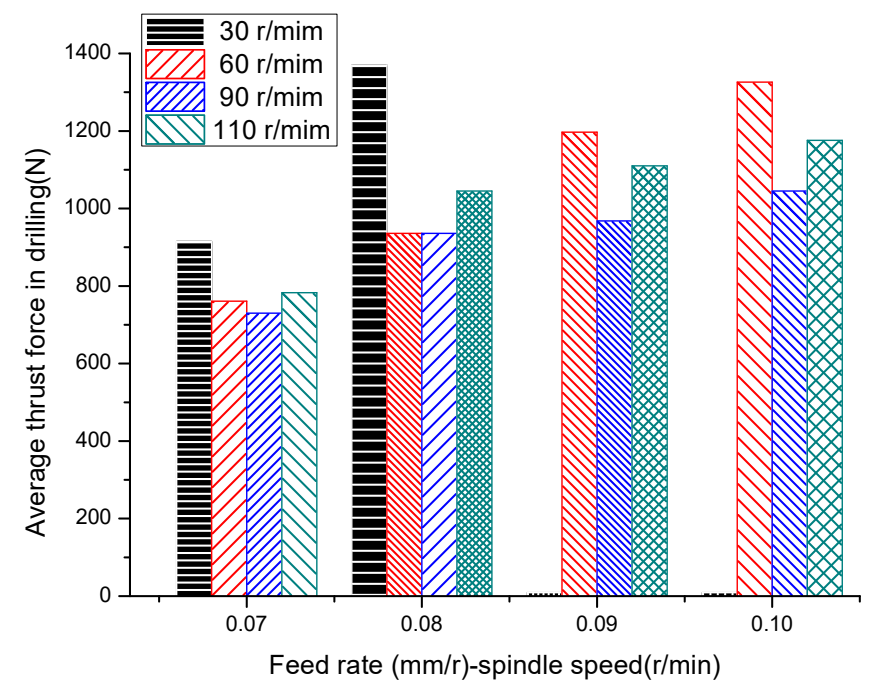

Figure 8. Thrust force when drilling

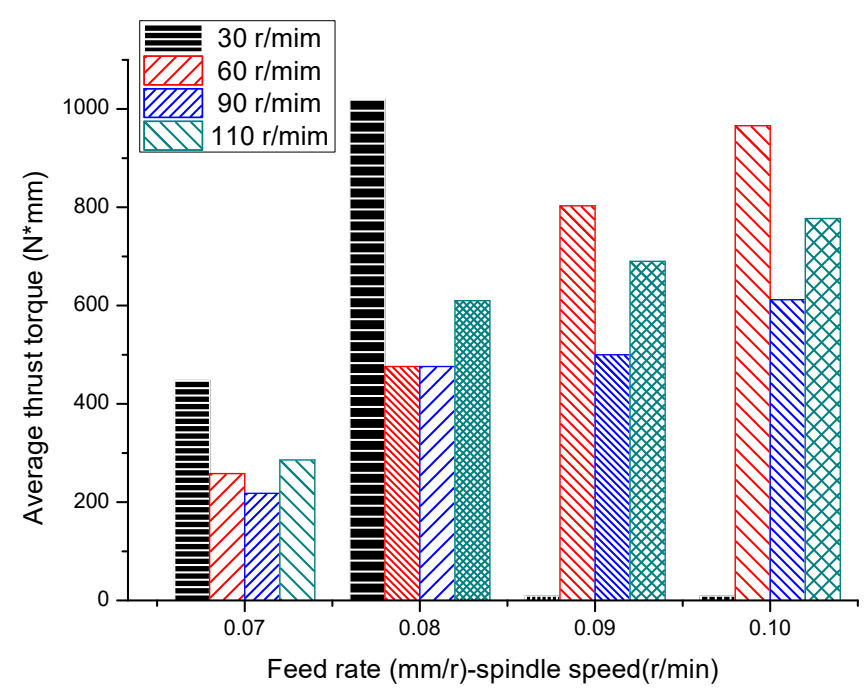

Figure 9. Thrust torque when drilling

Based on the data from dynamometer and knowledge of cutting principles, Excel 2005 was used to get the experimental formulas for force and torque. The result is followed.

$$
\begin{aligned}
& \mathrm{F}_{\mathrm{z}}=1560 \mathrm{Df}^{0.74} \mathrm{~V}^{0.29} . \\
& \mathrm{T}=4.40 \times 10^{-2} \mathrm{D}^{2} \mathrm{f}^{1.43} \mathrm{~V}^{0.67} .
\end{aligned}
$$

Where, Fz stands for thrust force, whose unit is $(\mathrm{N})$; D stands for drill diameter, whose unit is $(\mathrm{mm})$; f stands for axial feed per revolution, whose unit is $(\mathrm{mm})$; V stands for spindle speed, whose unit is $(\mathrm{r} \cdot \min -1)$; $\mathrm{T}$ stands for thrust torque, whose unit is $(\mathrm{N} \cdot \mathrm{mm})$.

The followed findings from those Eq.1 and Eq.2 are gotten. Thrust force and torque increases with the increase of spindle speed and feed rate, whose reason can be analyzed in following words. Firstly, increase in feed rate makes cutting thickness big, so increase cutting force, then thrust 
International Journal of Recent Advances in Mechanical Engineering (IJMECH) Vol.8, No.1, February 2019

force and torque increase; secondly, the spindle speed and feed rate increase feed rate per unit time of drilling, because of low elastic modulus of work-piece, elastic force to axial and pore walls increase, so the thrust force and torque increase. Finally, strain reinforcement of titanium alloys increases thrust force and torque under increased feed speed.

In order to validate decrease in burr when using the new be-burring tool designed, the comparative experiments were conducted and some comparisons were made in terms of burr width, burr height, and burr volume. Based on above experiment, the processing parameter in comparative experiment was followed. The feed rates were chosen from $0.08 \mathrm{~mm} / \mathrm{r}$ and $0.09 \mathrm{~mm} / \mathrm{r}$ and $0.10 \mathrm{~mm} / \mathrm{r}$, and the spindle speed equates to $60 \mathrm{r} / \mathrm{min}^{3}$. Fig.10 and Fig.11 and Fig.12 showed the comparative experiment's result.

Fig. 10 and Fig. 11 respectively show the exit burr widths and heights under different feed rates when using the new and traditional tools. Overall, the variation of the burr heights using new tool ranged between $30 \mu \mathrm{m}$ and $56 \mu \mathrm{m}$ at exit hole, while that of traditional tool did between $50 \mu \mathrm{m}$ and $65 \mu \mathrm{m}$. And the variation of the burr widths using new tool ranged between $176 \mu \mathrm{m}$ and $335 \mu \mathrm{m}$ at exit hole, while that of traditional tool did between $200 \mu \mathrm{m}$ and $400 \mu \mathrm{m}$. Fig. 12 shows the exit burr volumes under different spindle speeds and feed rates when using the new and traditional tools, the variation of the burr volume using new tool ranged between $0.048 \mathrm{~mm}^{3}$ and $0.29 \mathrm{~mm}^{3}$ at exit hole, while that of traditional tool did between $0.157 \mathrm{~mm}^{3}$ and $0.383 \mathrm{~mm}^{3}$.

From Fig.10, the exit burr width rate of traditional and new tools is between 1.14 and 1.28, which means the decrease in burr eight used new tool is $16 \% \sim 27 \%$ than that did the traditional tool.

From Fig.11, the exit burr height rate of traditional and new tools is between 1.13 and 1.26, which means the decrease in burr eight used new tool is $12 \sim 20 \%$ than that did the traditional tool.

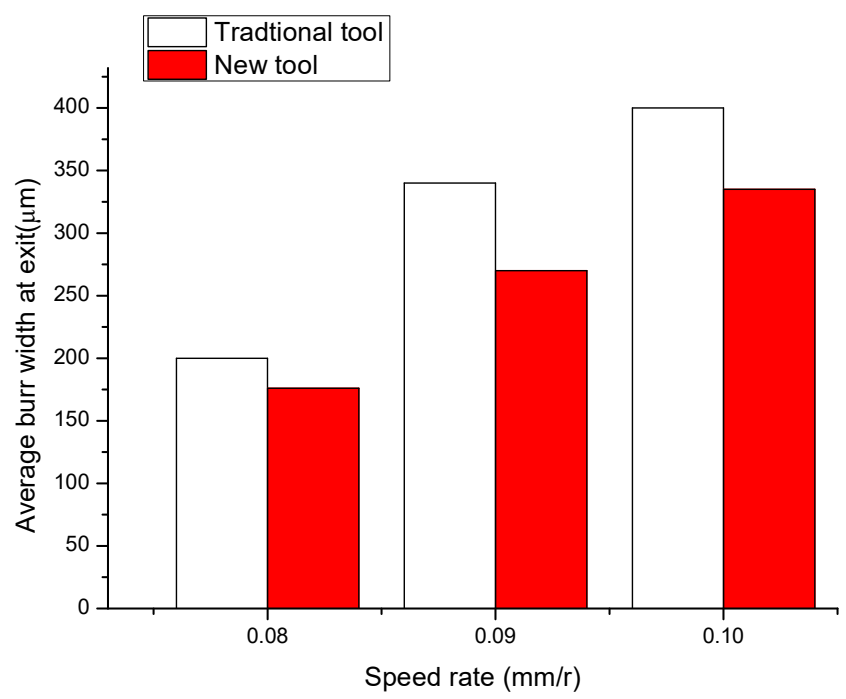

Figure 10. Average burr width at exit when using new tool 


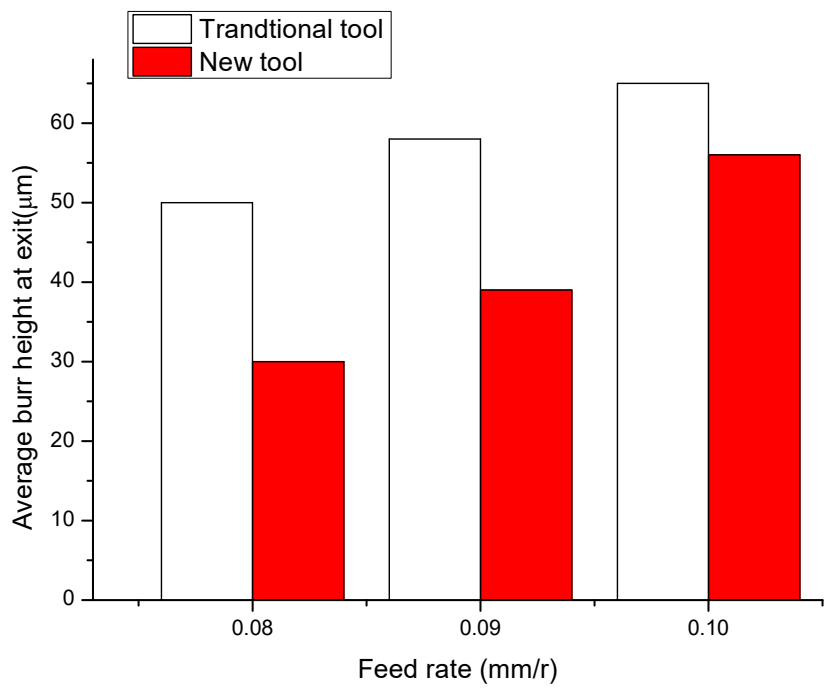

Figure 11. Average burr height at exit when using new tool

From Fig.12, the exit burr volume rate of traditional and new tools is between 1.3 and 3.2 separately, which means the decrease in burr height used new tool is $20 \% \sim 70 \%$ than that did the traditional tool. When the feed rate is smaller, the differential value between traditional and new tools is bigger.

The reason for above phenomena can be explained in following words. Work-piece deformed rate and transportation of chip during the drilling process can be attributed to characteristics of burr at exit. It is commonly thought that burr is the result of work-piece deformation under force and characteristics of work-piece, such as elastic modulus thermal conductivity. When new tool is used, the exit burr height and width is decreased, and the former is less than the latter, which leads to the promising results. First of all, the decrease in burr height and width bring out the volume reduction of burr at exit. Last but not least, decrease in burr width is more than that in burr height, which finally reduce time to remove burrs. Those result leads from the plastic deformation rate and accumulation deformation degree.

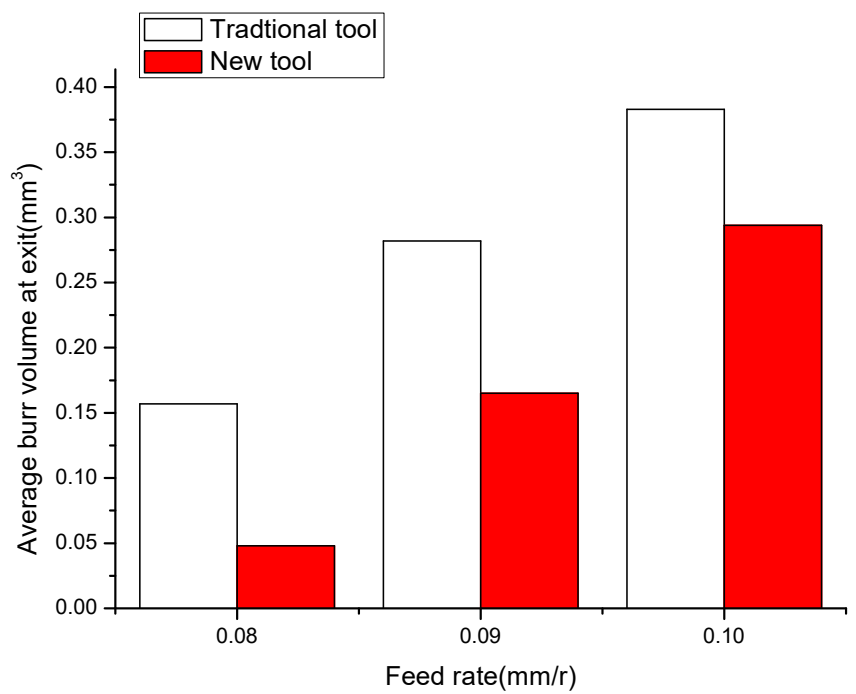

Figure 12. Average burr volume at exit when using new tool 
International Journal of Recent Advances in Mechanical Engineering (IJMECH) Vol.8, No.1, February 2019

\section{Conclusions}

Series experiments were conducted to investigate hole exit characteristics of Ti6Al4V drilled. Some findings can be gotten. (1).Axial feed rate takes the great effect on burr formation and volume compared to other processing parameters such as spindle speed. (2).Burr width has significant impact on working hours to de-burr hole edge, which determines the burr volume.(3).New designed tool can be used to decrease burr width and height, resulting into reduction of burr volume. And the promising result is to get the more reduction of the burr width than that of burr height, when comparing with use of traditional tool.

Hole exit quality has been one of the most difficult issues in manufacturing field, this work in paper is just the beginning and there are a lot of work to do in following years. Future work would be centred on determining the optical processing parameters to improve quality and reduce deburring time.

\section{ACKNOWLEDGEMENTS}

This work is funded by Research Program supported by the Shaanxi Provincial Department of Education (Shaanxi key laboratory research project (17JS060), China. We give thanks to Miss Lei liping for her great help in preparation for new tool desinged and Mir Jia zhongyi for improment suggestion in designing experiment.

\section{REFERENCES}

[1] Zhang Pf, Churi Nj, Pei Zj, Treadwell C, (2008) "This Is My Paper Mechanical Drilling Processes For Titanium Alloys: A Literature Review”, Mach Sci Tech, Vol. 12, No. 4, Pp417-444.

[2] Dornfeld DA, Kim JS, Dechow H, Hewson J, Chen LJ, (1999) "Drilling burr formation in titanium alloy Ti-6Al-4V”, CIRP Annals - Manuf Tech, Vol. 48, No. 1, pp73-76.

[3] Hocheng H, Tsao CC, (2008) "Computerized tomography and C-scan for measuring delamination in the drilling of composite materials”, Mach Tools Manuf, Vol. 45, No. 11, pp120-122.

[4] Lazoglu I, Poulachon G, Ramirez C, Akmal M, Marcon B, Rossi F, Outeiro J, Krebs M, (2017) “Thermal analysis in Ti-6Al-4V drilling” CIRP Annals - Manuf Tech, Vol. 66, No. 1, pp105-108.

[5] Patne H S, Kumar A, Karagadde S, Joshi S S, (2017) "Modelling of temperature distribution in drilling of titanium”, ABC Mech, Vol. 133, No. 11, pp120-122.

[6] Sharif S, Rahim EA, (2007) "Performance of coated-and uncoated-carbide tools when drilling titanium alloy-Ti6A14V”, Mater Process Tech, Vol. 185, No. 1, pp72-76.

[7] Wong FR, Sharif S, Kamdani K, Rahim EA (2008) "The effect of drill point geometry and drilling technique on tool life when drilling titanium alloy, Ti-6Al-4V", Proc Int Conf Mech Manuf Eng (ICME2008), 21-23 May 2008, Johor Bahru, Malaysia.

[8] Rahim E, Sasahara H, (2011) "A Study of the Effect of Palm Oil as MQL Lubricant on High Speed Drilling of Titanium Alloys”, Tribol Int, Vol. 44, No. 3, pp309-317.

[9] Brinksmeier E, Pecat O, Rentsch R, (2015) "Quantitative analysis of chip extraction in drilling of Ti6Al4V”, CIRP Annals - Manuf Tech, Vol. 64, No. 1, pp93-86

[10] Brinksmeier E, Pecat O, Rentsch R, (2009) "A Drilling process optimization for graphite/bismaleimide titanium alloy stacks", Compos Struct, Vol. 63, No. 1, pp101-114. 
International Journal of Recent Advances in Mechanical Engineering (IJMECH) Vol.8, No.1, February 2019

[11] Park K, Beal A, Kim D, Kwon P, Lantrip J, (2008) "Tool wear in drilling of composite/titanium stacks using carbide and polycrystalline diamond tools”, Wear, Vol. 271, No. 9-10, pp2826-2835.

[12] Ramulu M, Branson T, Kim D (2001) "A study on the drilling of composite and titanium stacks", Compos Struct, Vol. 54, No. 10, pp67-74.

[13] Sapkal SU, Jagtap PS (2018)“Optimization of Micro EDM Drilling Process Parameters for Titanium Alloy by Rotating Electrode”, Procedia Manuf, Vol. 20, pp199-126.

[14] Plaza S, Sanchez JA, Perez E, Gil R, Izquierdo B, Ortega N, Pombo I (2014) "Experimental study on micro EDM-drilling of Ti6A14V using helical electrode", Precis Eng, Vol. 38, No. 4, pp821-827.

[15] Sakurai T, Fijintani K, Katsushige A, Ogama K,(1992) "Low-frequency vibration drilling of titanium alloy”, Jpn Inst Light Met, Vol. 42, No. 5, pp633-637.

[16] Sharifa S, Rahim O (2007) "Performance of coated and uncoated carbide tols when drillin titanium allay Ti -6Al-4V”, Mater Process tech, Vol. 185, No. 1, pp76-76.

\section{AUTHORS}

Dr. Quanli Han obtained his B.S. Degree at Xian Mining Institute in China in 1997, and completed his M.S. with Prof. Yushan Xu at Xian Science and Technology Institute in 2001 and got Ph. D with Prof. Xipeng Xu at HuaQiao University in 2008 respectively. He joined Xian Technological University in January 2009. Until now, he has published 10+ papers. His current research is focused on the functional surface design and application, precision machining of large ceramic surfaces, etc.

Dr. Hongqiang Wan obtained his B.S. Degree at Northwest Textile Institute in China in 1999, and completed his M.S. and Ph. D with Prof. Yixuan Wang and Liang Wang at Northwest Polytechnical University in 2004 and 2010 respectively. He joined Xian Technological University in January 2007. Until now, he has published10+ patent applications $20+$ papers. His current research is focused on precision machining, complex institutional design, etc.
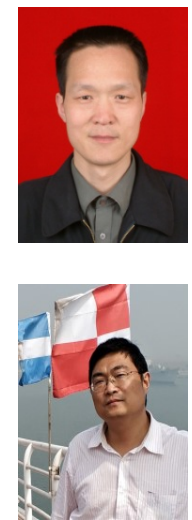